\title{
Tratamento de esgotos sanitários em sistemas reatores UASB/wetlands construídas de fluxo horizontal: eficiência e estabilidade de remoção de matéria orgânica, sólidos, nutrientes e coliformes
}

\section{Domestic wastewater treatment in UASB-horizontal flow constructed wetlands systems: organic matter, solids, nutrients and coliforms removal}

\begin{abstract}
Maria Lúcia Calijuri
Engenheira Civil pela Universidade de São Paulo (USP). Mestre em Geotecnia (USP). Doutora em Geotecnia (USP). Professora Titular do Departamento de Engenharia Civil da Universidade Federal de Viçosa (UFV)

\section{Rafael Kopschitz Xavier Bastos}

Engenheiro Civil pela Universidade Federal de Juiz de Fora (UFJF). Especialização em Engenharia de Saúde Pública pela Escola Nacional de Saúde Pública da Fundação Oswaldo Cruz (ENSP/Fiocruz). PhD em Engenharia Sanitária pela University of Leeds. Professor-Associado do Departamento de Engenharia

Civil da UFV
\end{abstract}

\author{
Tiago de Brito Magalhães \\ Graduando em Engenharia Ambiental da UFV
}

Bruna Cesca Capelete

Engenheira Ambiental da UFV

\section{Edgard Henrique Oliveira Dias}

Graduando em Engenharia Ambiental da UFV

\section{Resumo}

Este trabalho apresentou os resultados de um estudo realizado durante 19 meses sobre o comportamento de wetlands construídas na remoção de matéria orgânica, sólidos, nutrientes e coliformes, em unidades em escala piloto de fluxo horizontal, subsuperficial e superficial, com tempo de detenção hidráulica entre 1,3 a 5,3 dias, operando como pós-tratamento de efluentes de reatores UASB (esgotos sanitários). A remoção de matéria orgânica e de sólidos mostrouse elevada e estável, com eficiências médias de 70, 80 e 60\% para SST, DBO e DQO, respectivamente. A remoção de nutrientes, após início promissor, mostrou-se instável e aparentemente influenciada pela temperatura. O sistema de tratamento revelou elevado potencial de remoção de coliformes, embora com variações relativamente amplas ao longo do período de operação: $\approx 2 \log _{10}$ de remoção de coliformes totais e 2-4 $\log _{10}$ de remoção de Escherichia coli.

Palavras-chave: Brachiaria arrecta; fluxo horizontal; Typha sp.; wetlands construídas.

\section{Abstract}

This work presented the results of a 19-month study on the performance of constructed wetlands in terms of organic matter, solids, nutrients and coliforms removal in pilot scale unities with horizontal, subsurface and surface flow, with hydraulic retention time from 1.3 to 5.3 days, as post-treatment of UASB effluents (domestic wastewater). Organic matter and solids were effectively and consistently removed, with average values of 70,80 and $60 \%$ for TSS, BOD ${ }_{5}$ and $\mathrm{COD}_{\text {, }}$ respectively. Nutrients removal, after a promising start up, became unstable and apparently influenced by temperature. The treatment system has also shown high potential to remove coliforms, although with relatively wide variations over the study period: $\approx 2 \log _{10}$ reduction of total coliforms and $2-4$ log ${ }_{10}$ reduction of Escherichia coli.

Keywords: Brachiaria arrecta; horizontal flow; Typha sp; constructed wetlands. 


\section{Introdução}

A tecnologia anaeróbia aplicada ao tratamento de esgotos sanitários encontra-se bem consolidada e resulta, dentre outras vantagens, em grandes economias de área. Entretanto, esses sistemas apresentam capacidade limitada de remoção de matéria orgânica e pequena, se alguma, de remoção de nutrientes e patógenos, em geral demandando pós-tratamento, seja para o lançamento em corpos receptores, seja para o reúso (CHERNICHARO, 2001).

Wetlands construídas (WC) podem constituir boa opção para o pós-tratamento de efluentes anaeróbios, pois comprovadamente apresentam elevada capacidade de remoção de demanda bioquímica de oxigênio (DBO), demanda química de oxigênio (DQO) e sólidos, assim como de nutrientes e de organismos indicadores de contaminação, muito embora, nesses casos, com informações mais escassas e/ ou menos precisas (USEPA, 2000; KADLEC et al., 2000; MBWETTE; KATIMA e JØRGENSEN, 2001; STOTT; MAY e MARA, 2003).

Basicamente, esses sistemas são constituídos de canais preenchidos por meio poroso com alta condutividade hidráulica (usualmente cascalho, areia grossa ou brita), o qual dá suporte ao crescimento de macrófitas e de biofilme, além do fundamental papel de atuar como filtro para alguns poluentes. As WC podem ser classificadas de acordo com o fluxo (vertical ou horizontal), o qual ainda é dividido em fluxo superficial (FS) e subsuperficial (FSS) (USEPA, 2000).

O emprego de WC para o tratamento de esgotos sanitários tem crescido substancialmente em várias partes do mundo, particularmente em instalações de pequeno porte. A literatura científica já reúne considerável acervo de estudos de monitoramento e tentativas de modelagem de funcionamento desses sistemas (USEPA, 2000; KADLEC et al., 2000; MBWETTE; KATIMA e JØRGENSEN, 2001), muito embora, como já referido, ainda persistam importantes lacunas de informações, principalmente em países de clima tropical. No Brasil, o interesse e os estudos sobre WC são também crescentes, ainda que relativamente recentes. Entretanto, a maioria das informações disponíveis refere-se a instalações em escala piloto e/ou a estudos em períodos de operação/monitoramento relativamente curtos (VALENTIM, 1999; NOGUEIRA, 2003; VALENTIM, 2003; SOUSA; VAN HAANDEL e LIMA, 2004; BRASIL, 2005).

Este trabalho teve como objetivo contribuir para a discussão sobre o desempenho de WC na remoção de matéria orgânica, sólidos, nutrientes e coliformes. Apresentam-se resultados de um estudo desenvolvido durante 19 meses com unidades de fluxo horizontal, subsuperficial e superficial, operando como pós-tratamento de reatores UASB (esgotos sanitários).

\section{Material e métodos}

Os experimentos foram conduzidos na Unidade Experimental de Tratamento de Esgotos e Utilização de Efluentes da Violeira,
Viçosa (MG). A estação de tratamento de esgotos (ETE) experimental era constituída por um reator UASB em escala real, pré-fabricado em aço $\left(Q_{\text {med }}=115 \mathrm{~m}^{3} \cdot \mathrm{d}^{-1}\right.$, volume $=48 \mathrm{~m}^{3}$, altura $=5,70 \mathrm{~m}$ e TDH $=7 \mathrm{~h}$ ), seguido de um sistema de WC de fluxo horizontal, composto por quatro unidades-piloto em paralelo, construídas em alvenaria e tendo como meio suporte mescla de brita \# 0 e 1 . O dimensionamento das WC foi realizado com base na remoção de nitrogênio, segundo modelo de cinética de primeira ordem e fluxo em pistão (REED et al., 1995), assumindo como critério de projeto efluente com $20 \mathrm{mg} \mathrm{NH}_{3} \cdot \mathrm{L}^{-1}$ (Equações 1 e 2).

$N H_{3 e f l}=N T K_{a f l} \cdot e^{\left(-K_{N T} \cdot T D H\right)}$

Equação 1

$K_{N T T}=K_{N T 20} \cdot 1,048^{(T-20)}$

Equação 2

onde:

$\mathrm{NH}_{3 \text { efl }}$ : concentração de $\mathrm{N}-\mathrm{NH}_{3}$ no efluente (mg. $\left.\mathrm{L}^{-1}\right)$;

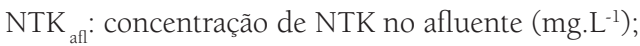

$\mathrm{K}_{\mathrm{NT}}$ : coeficiente de remoção de $\operatorname{NTK}\left(\mathrm{d}^{-1}\right)$;

TDH: tempo de detenção hidráulica (d);

$\mathrm{K}_{\mathrm{NT}}$ : coeficiente de remoção de NTK à temperatura $\mathrm{T}\left(\mathrm{d}^{-1}\right)$;

$\mathrm{K}_{\mathrm{NT} 20}$ : coeficiente de remoção de NTK à $20^{\circ} \mathrm{C}\left(\mathrm{d}^{-1}\right)$;

T: temperatura $\left({ }^{\circ} \mathrm{C}\right)$.

O experimento foi dividido em três fases operacionais, variandose o tipo de fluxo, a espécie de macrófita e a vazão (por conseguinte, o tempo de detenção hidráulica, TDH, e a taxa de aplicação hidráulica superficial, TAS) com o intuito de avaliar a influência dessas variáveis no desempenho das WC:

(i) Fase 1: duas unidades de FS e outras duas de fluxo subsuperficial (FSS); cada tipo de fluxo apresentava uma unidade plantada com Typha sp. (Taboa) e outra com Brachiaria arrecta (braquiária do brejo);

(ii) Fases 2 e 3: as quatro unidades em paralelo passaram a operar com FSS, sendo a vazão afluente a única diferença entre essas duas fases (Tabela 1).

Apesar deste delineamento, os resultados reunidos acabaram por não permitir análise detalhada da influência de cada variável (por exemplo, por meio de testes estatísticos). Sendo assim, a discussão é feita com base em abordagem descritiva, procurando-se, na medida do possível, destacar efeitos daquelas variáveis que mais nitidamente parecem ter influenciado o desempenho do sistema.

O sistema foi monitorado de novembro de 2006 a maio de 2008, por meio de amostragem dos efluentes em frequência semanal, de forma composta (das 8 às 18h, a cada duas horas), para os parâmetros físicos e químicos, e quinzenalmente, de forma pontual (pela manhã) para os parâmetros microbiológicos. Foram coletadas 
Tabela 1 - Características operacionais das unidades wetlands, Unidade Experimental de Tratamento de Esgotos e Utilização de Efluentes da Violeira, Viçosa (MG)

\begin{tabular}{|c|c|c|c|c|c|}
\hline Unidade & & W1 & W2 & W3 & W4 \\
\hline Vegetação (espécie) & & Typha & Brachiaria & Brachiaria & Typha \\
\hline Largura $(\mathrm{m})$ & & 2 & 2 & 1,7 & 1,7 \\
\hline Comprimento $(\mathrm{m})$ & & 12 & 12 & 8,6 & 8,6 \\
\hline Fase $1(n=33)$ & Tipo de fluxo & FS & FS & FSS & FSS \\
\hline \multirow[t]{3}{*}{ (novembro de 2006 a agosto de 2007) } & $\mathrm{TDH}$ (dias) & 4,5 & 4,5 & 2,9 & 2,9 \\
\hline & $Q\left(m^{3} \cdot d^{-1}\right)$ & 1,5 & 1,5 & 1,5 & 1,5 \\
\hline & TAS $\left(m^{3} \cdot m^{-2} \cdot d^{-1}\right)$ & 0,063 & 0,063 & 0,103 & 0,103 \\
\hline Fase $2(n=13)$ & Tipo de fluxo & FSS & FSS & FSS & FSS \\
\hline \multirow[t]{3}{*}{ (setembro de 2007 a fevereiro de 2008) } & TDH (dias) & 5,3 & 5,3 & 3,2 & 3,2 \\
\hline & $Q\left(m^{3} \cdot d^{-1}\right)$ & 1 & 1 & 1 & 1 \\
\hline & TAS $\left(m^{3} \cdot m^{-2} \cdot d^{-1}\right)$ & 0,042 & 0,042 & 0,069 & 0,069 \\
\hline Fase $3(n=6)$ & Tipo de fluxo & FSS & FSS & FSS & FSS \\
\hline \multirow[t]{3}{*}{ (março a maio 2008) } & $\mathrm{TDH}$ (dias) & 2,2 & 2,2 & 1,3 & 1,3 \\
\hline & $Q\left(m^{3} \cdot d^{-1}\right)$ & 2,5 & 2,5 & 2,5 & 2,5 \\
\hline & TAS $\left(m^{3} \cdot m^{-2} \cdot d^{-1}\right)$ & 0,104 & 0,104 & 0,171 & 0,171 \\
\hline
\end{tabular}

FS: fluxo superficial; FSS: fluxo subsuperficial; Q: vazão; TDH: tempo de detenção hidráulica; TAS: taxa de aplicação hidráulica superficial; n: número de eventos de coleta de amostras.

amostras de Brachiaria para determinação da produtividade e análise bromatológica, em intervalos de cerca de três meses.

As análises físicas, químicas e bacteriológicas (coliformes totais e Escherichia coli, com emprego de método cromogênico) seguiram, essencialmente, as disposições do Standard Methods for the Examination of Water and Wastewater (APHA; AWWA; WEF, 1998). As vazões eram ajustadas três vezes ao dia por medição direta (método volumétrico).

\section{Resultados e discussão}

\section{Desempenho do reator UASB}

Durante o período considerado, o reator UASB apresentou elevada remoção de $\mathrm{DBO}_{5}$, DQO e SST e capacidade de amortecer as variações das concentrações afluentes: valores médios de 77 a 84\% (DBO), 69 a 75\% (DQO), respectivamente nos meses mais frios e mais quentes (definidos no item a seguir) e 76\% como média geral para SST. Observou-se, também como média geral, remoção de fósforo em torno de 15\%, além de notável conversão de parte do nitrogênio orgânico em nitrogênio amoniacal (em geral, em torno de $40 \%$, sendo cerca de 30 e $50 \%$, respectivamente nos períodos quente e frio). Como esperado, a remoção de coliformes mostrou-se limitada: $87 \%\left(0,89 \log _{10}\right)$ para coliformes totais e $67 \%\left(0,48 \log _{10}\right)$ para E. coli. Mesmo o reator UASB apresentando elevada eficiência de remoção de matéria orgânica e de sólidos, confirma-se a necessidade do polimento de seu efluente. A Tabela 2 resume os resultados, em termos de valores médios e desvios padrão, referentes a todo o período de monitoramento (parâmetros físicos e químicos).

\section{Temperatura do líquido}

As variações dos valores médios diários de temperatura do líquido (medida nos efluentes das WC) ao longo do período
Tabela 2 - Caracterização do esgoto bruto e do efluente do reator UASB, média e desvio padrão, Unidade Experimental de Tratamento de Esgotos e Utilização de Efluentes da Violeira, Viçosa (MG), novembro de 2006 a maio de 2008

\begin{tabular}{lcc} 
& \multicolumn{2}{c}{ Pontos de coleta } \\
\cline { 2 - 3 } Parâmetros analisados & EB (DP) & UASB (DP) \\
$\mathrm{DBO}_{5}$ & $308(110)$ & $50(24)$ \\
$\mathrm{DQO}$ & $746(267)$ & $191(102)$ \\
$\mathrm{SST}$ & $256(108)$ & $60(44)$ \\
$\mathrm{NTK}$ & $55(23)$ & $55(27)$ \\
$\mathrm{N}-\mathrm{NH}_{3}$ & $33(17)$ & $43(14)$ \\
$\mathrm{N}$-org & $22(9)$ & $12(19)$ \\
P-total & $9,5(4,6)$ & $8,1(2,5)$ \\
\hline
\end{tabular}

EB: esgoto bruto; UASB: efluente do UASB; DP: desvio padrão Resultados em mg.L-1; valores entre parênteses: desvio padrão.

experimental estão apresentadas na Figura 1, divididos em dois períodos: maio a setembro (como representativos dos meses mais frios) e outubro a abril (meses mais quentes). Ressalta-se a diferença de temperatura entre os dois períodos (valores medianos em torno de $7^{\circ} \mathrm{C}$ ) e a maior amplitude de variação apresentada durante os meses mais frios.

\section{Remoção de sólidos e matéria orgânica}

Na Figura 2, encontram-se os resultados (expressos em gráficos boxplot) do monitoramento de $\mathrm{DBO}_{5}$ e sólidos em suspensão totais (SST) nos efluentes das unidades de tratamento. Foram registradas remoções médias de cerca de 70, 80 e 60\% para SST, $\mathrm{DBO}_{5}$ e DQO, respectivamente. O efluente do UASB já apresentava concentrações médias de SST e DBO relativamente baixas, ambas abaixo de $70 \mathrm{mg} \cdot \mathrm{L}^{-1}$, mas, ainda assim, as WC promoveram elevada remoção complementar, independentemente da unidade ou fase operacional considerada, produzindo efluentes com concentrações raramente superiores a $15 \mathrm{mg}$ DBO.L $\mathrm{L}^{-1}$ e $20 \mathrm{mg}$ SST.L $\mathrm{L}^{-1}$. Os resultados apresentaram baixa variabilidade, não sendo observadas influências nítidas do 


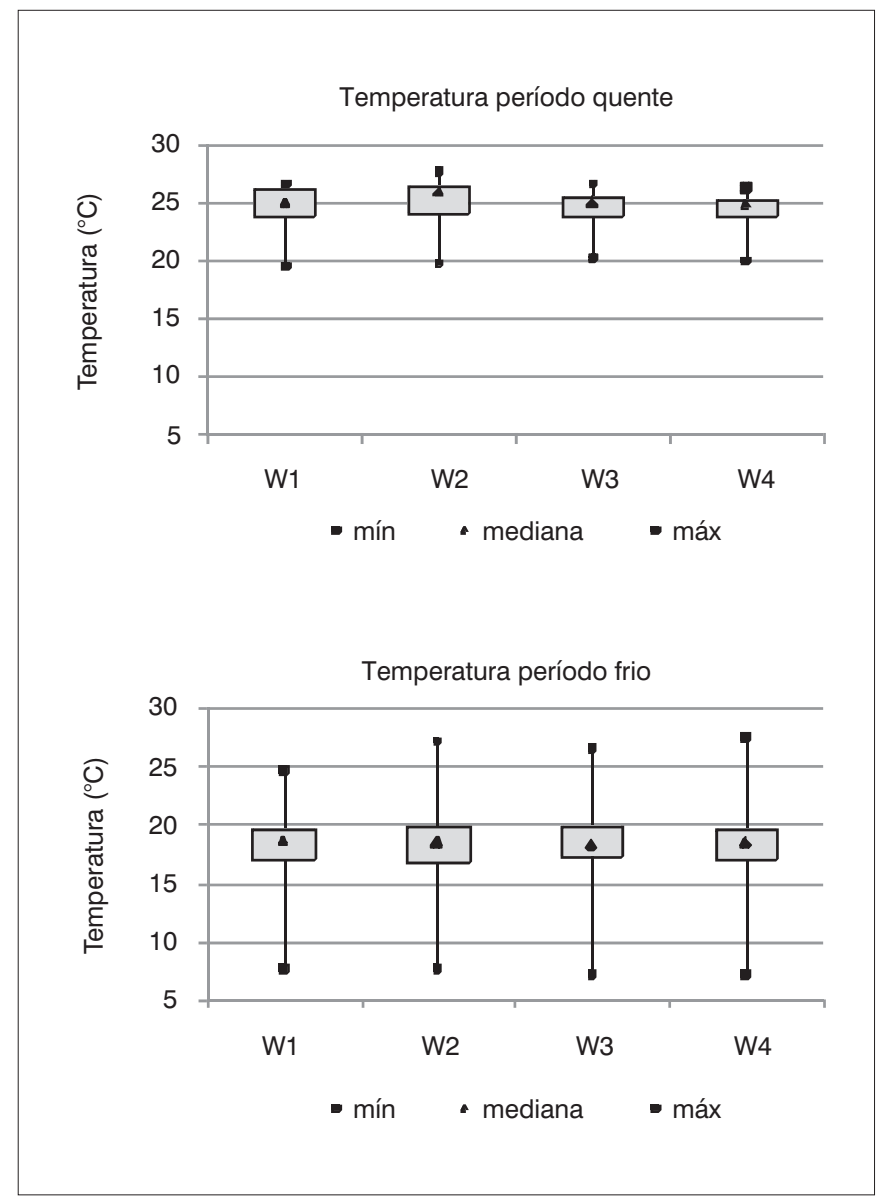

Figura 1 - Variação da temperatura média diária do líquido nas unidades wetlands, em períodos quente e frio, Unidade Experimental de Tratamento de Esgotos e Utilização de Efluentes da Violeira, Viçosa (MG), novembro de 2006 a maio de 2008

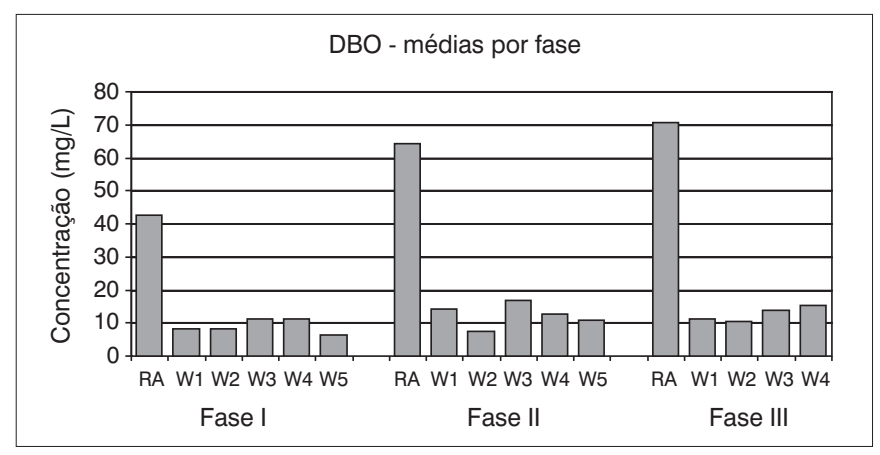

Figura 3 - Concentrações médias de DBO nos efluentes do reator UASB e das wetlands, por fase operacional, Unidade Experimental de Tratamento de Esgotos e Utilização de Efluentes da Violeira, Viçosa (MG), novembro 2006 a junho de 2008

tempo de operação ou da temperatura, no que diz respeito à remoção de DBO e de SST (Figuras 2 e 3).

A remoção de matéria orgânica suspensa, sedimentável ou solúvel é, em geral, muito elevada em WC e se dá por processos físicos e biológicos, como a sedimentação, que ocorre em razão da baixa velocidade de escoamento, a filtração, pela presença de raízes e rizomas,
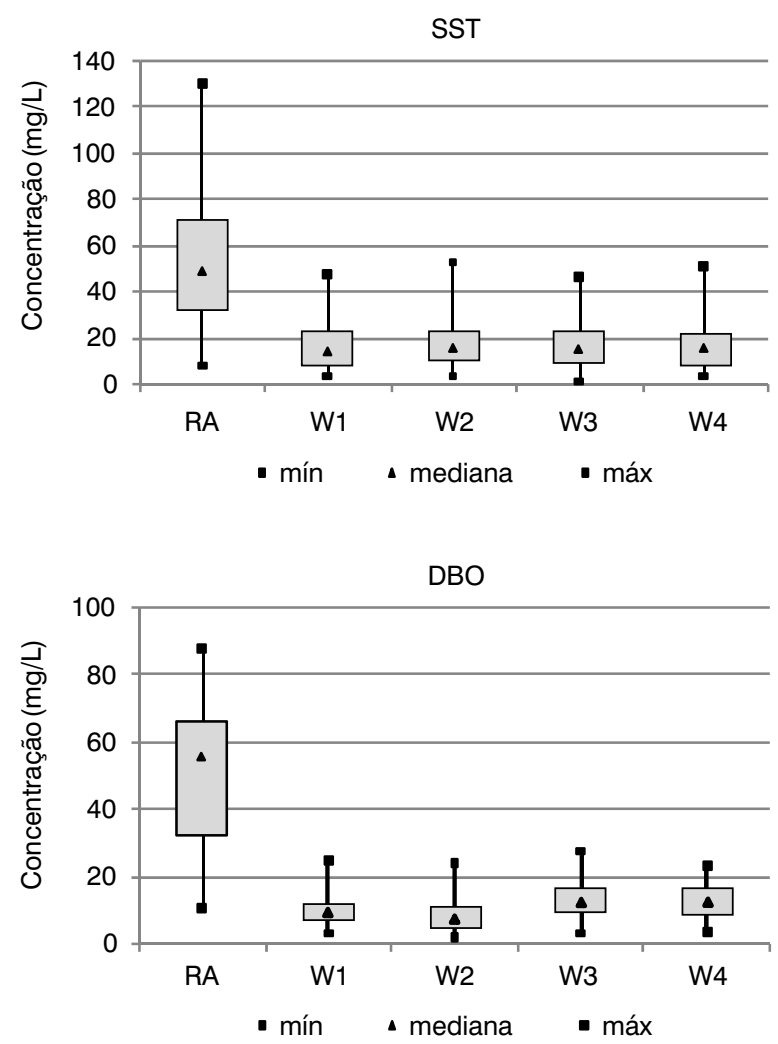

Figura 2 - Variação das concentrações de SST e DBO nos efluentes do reator UASB e das unidades wetlands, Unidade Experimental de Tratamento de Esgotos e Utilização de Efluentes da Violeira, Viçosa (MG), novembro de 2006 a maio de 2008

além do crescimento de bactérias que se desenvolvem dispersas no meio líquido e aderidas ao biofilme formado, promovendo a degradação desses poluentes (USEPA, 1988).

Os resultados do presente trabalho confirmam essa expectativa, já registrada em vários outros trabalhos com WC de fluxo horizontal subsuperficial, recebendo efluente de tratamento secundário, como: Vymazal (1996), na República Tcheca (77 a 98\% de remoção de DBO, 59 a 91\% de DQO e 77 a 99\% de SST); Sousa et al. (2004) em Campina Grande (PB), efluente de reator UASB com TDH de dez dias (70 a 86\% de remoção de DQO); Brasil (2005), em Viçosa (MG), efluente de tanque séptico TDH = 1,9 a 3,6 dias (87 a 90\% (DQO) e $91 \%$ (SST)).

\section{Remoção de nutrientes}

Na Figuras 4 e 5, apresentam-se, respectivamente, as variações temporais das concentrações de nitrogênio e de fósforo nos efluentes das unidades de tratamento. Em relação ao nitrogênio, todas as unidades WC apresentaram comportamento inconstante ao longo do período experimental: remoção de nitrogênio total Kjeldahl 


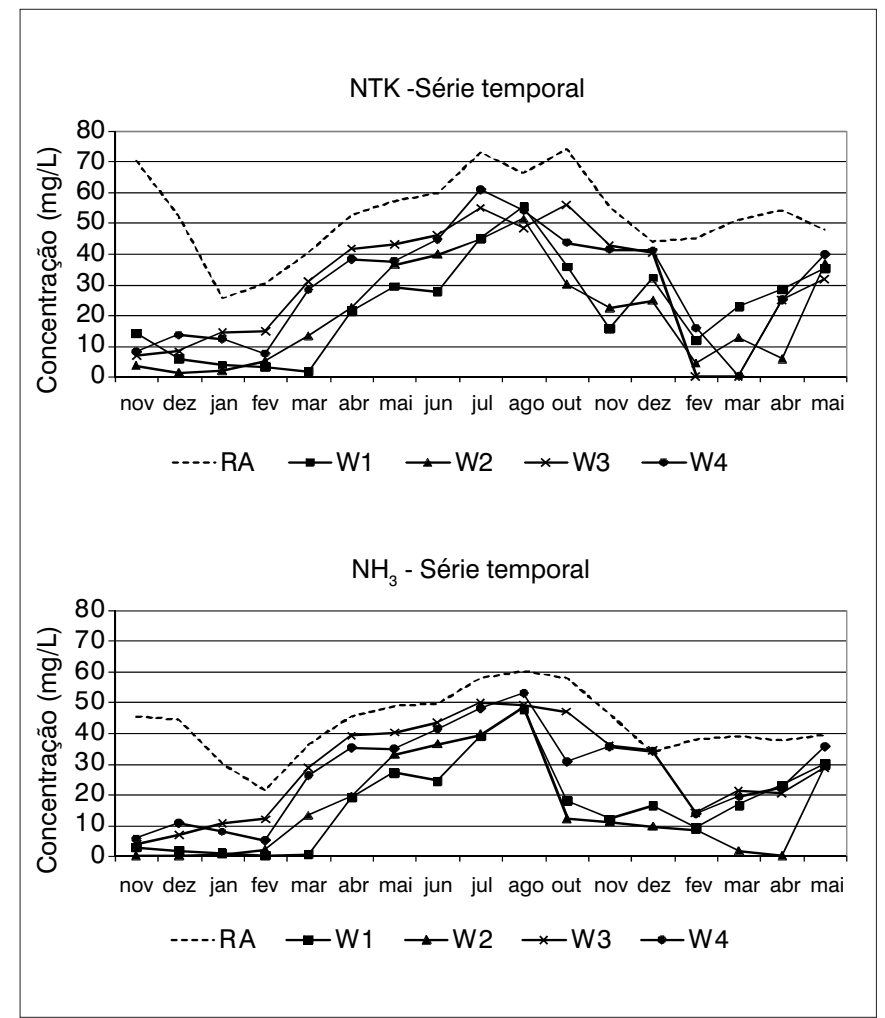

Figura 4 - Variação temporal das concentrações de NTK e $\mathrm{NH}_{3}$ noS efluentes do reator UASB e das unidades wetlands, Unidade Experimental de Tratamento de Esgotos e Utilização de Efluentes da Violeira, Viçosa (MG), novembro de 2006 a maio de 2008

(NTK) entre 22 e $67 \%$, e de nitrogênio amoniacal $\left(\mathrm{N}^{-\mathrm{NH}_{3}}\right)$ entre 23 e $82 \%$. As variações temporais das concentrações efluentes de NTK e $\mathrm{NH}_{3}$ revelaram comportamentos semelhantes: remoção muito elevada no início do funcionamento do sistema, demonstrando a capacidade do sistema em amortecer as cargas afluentes do reator UASB, seguida, entretanto, de ciclos de queda e ganho de desempenho (Figura 4).

Durante as três fases operacionais, a eficiência de remoção de P-total variou de 25 a 79\% (valores médios por unidade e fase operacional). Esse dado de remoção mais elevada (W2, Fase 3) deve, entretanto, ser visto com cautela (bem como o de remoção de $\mathrm{N}-\mathrm{NH}_{3}$ ), pois se refere a uma fase operacional com poucos eventos de amostragem (Tabela 1). À semelhança das variações observadas para o nitrogênio, no início da operação, a remoção de fósforo foi muito elevada. Porém, seguiram-se períodos de queda e, subsequentemente, de melhoria de desempenho do sistema (Figura 5); registram-se, inclusive, episódios de concentrações efluentes de P-total superiores às afluentes, durante os meses mais frios.

Informações de literatura sobre a eficiência de remoção de $\mathrm{N}$ e P alcançada em WC são as mais variadas. Por exemplo, em relação ao nitrogênio, Brasil (2005), em Viçosa, registra 33 a 57\% de remoção de NTK (TDH = 1,9 a 3,6 dias); Nyakang'o e van Bruggen (1999), no Quênia, remoção de 90\% de NTK e 92\% de N-NH

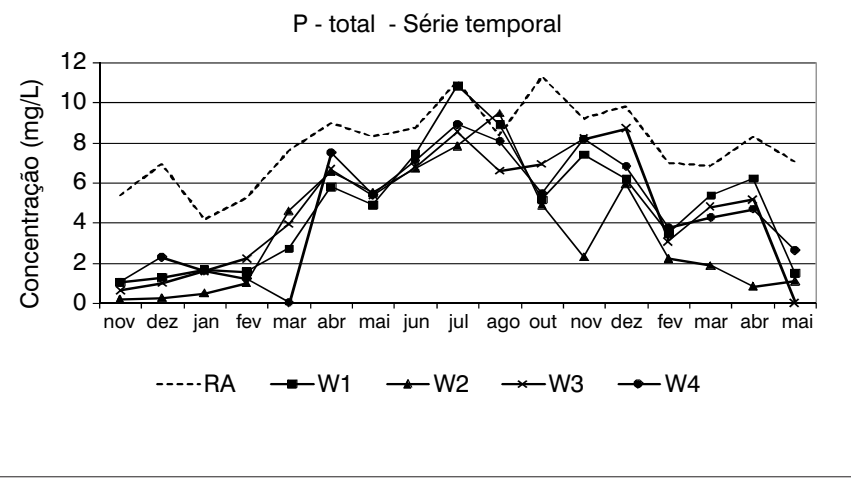

Figura 5 - Variação temporal da concentração de P-total nos efluentes do reator UASB e das unidades wetlands, Unidade Experimental de Tratamento de Esgotos e Utilização de Efluentes da Violeira, Viçosa (MG), novembro de 2006 a maio de 2008

remoção média de nitrogênio inferior a $60 \%$ em pesquisa com 41 sistemas em escala real na República Tcheca. Para fósforo total, Brasil (2005) registra remoção média entre 35 e 48\%, resultados superiores aos valores obtidos por Valentim (2003), em Campinas, São Paulo, (máximo de 23\%). Além disso, a exemplo do encontrado no presente trabalho, Sousa et al. (2004) encontraram grandes oscilações temporais, com queda de desempenho ao longo do período de operação do sistema:

(i) remoção de nitrogênio: 60 a 70\% (primeiro ano), 40 a 50\% (segundo ano), 50 a $60 \%$ (terceiro ano);

(ii) remoção de fósforo: 80 a 90\% (primeiro ano), 15 a 30\% (segundo ano), 15\% (terceiro ano).

Outros trabalhos também reportam tendência de remoção inicial elevada seguida de queda (VYMAZAL, 1996; 2004). Sousa et al. (2004) creditaram tais oscilações, supostamente, ao ciclo vegetativo das plantas, as quais, na fase de envelhecimento, não absorvem nutrientes na mesma proporção da fase de crescimento. Isso ajudaria a explicar o comportamento temporal observado no presente trabalho, como o adendo (ou a ressalva) de que os cortes periódicos (aproximadamente a cada três a quatro meses) nem sempre parecem ter renovado a capacidade de assimilação de nutrientes do sistema (Figura 4).

No que diz respeito aos fatores que podem ter influído na remoção de nutrientes, a influência da temperatura na remoção de nitrogênio parece nítida ao se computar os coeficientes de remoção de NTK $\left(\mathrm{K}_{\mathrm{NT20}}\right)$, de acordo com as Equações 1 e 2, para os períodos de temperaturas mais e menos elevadas (outubro a abril e maio a setembro, respectivamente) (Tabela 3). Em relação ao fósforo, notam-se também valores de eficiência mais elevados nos meses mais quentes, principalmente nas unidades com maior TDH (W1 e W2) (Figura 6). O desenvolvimento mais intenso das macrófitas, somado à maior 
Tabela 3 - Coeficientes de remoção de NTK (KNT20) (d-1) nas unidades wetlands nos períodos quente e frio, Unidade Experimental de Tratamento de Esgotos e Utilização de Efluentes da Violeira, Viçosa (MG), novembro de 2006 a maio de 2008

\begin{tabular}{lcccc} 
Período & W1 & W2 & W3 & W4 \\
\hline Frio & 0,12 & 0,09 & 0,11 & 0,12 \\
\hline Quente & 0,22 & 0,25 & 0,19 & 0,2
\end{tabular}

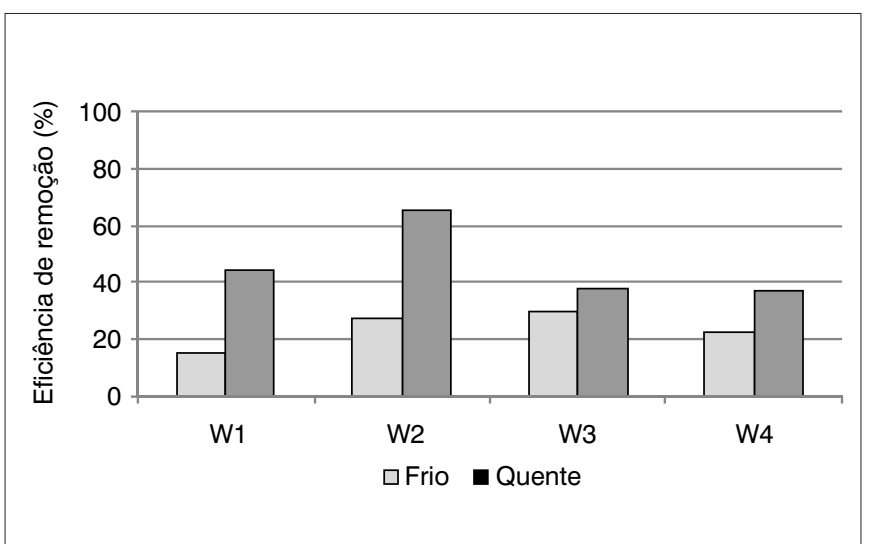

Figura 6 - Eficiência de remoção de P-total nas unidades wetlands nos períodos quente e frio, Unidade Experimental de Tratamento de Esgotos e Utilização de Efluentes da Violeira, Viçosa (MG), novembro de 2006 a maio de 2008

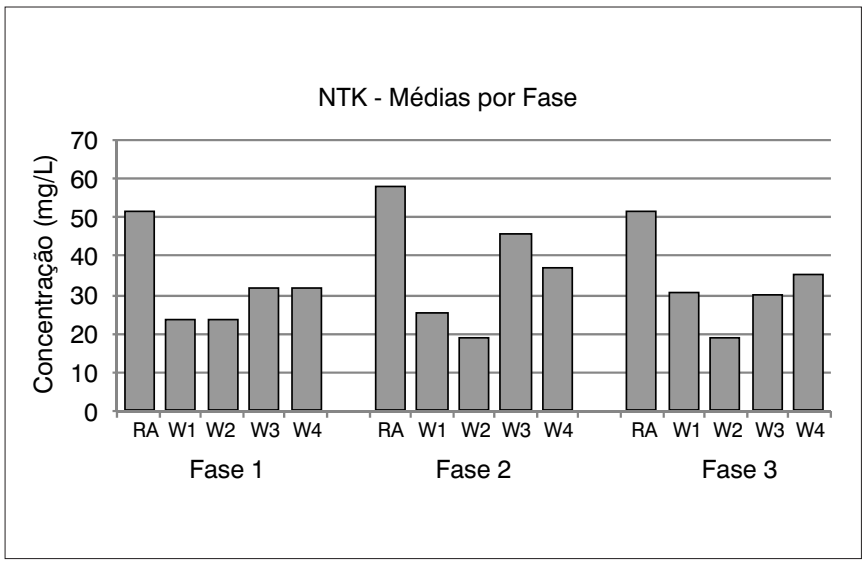

Figura 7 - Concentração média efluente de NTK nas unidades wetlands por fase operacional, Unidade Experimental de Tratamento de Esgotos e Utilização de Efluentes da Violeira, Viçosa (MG), novembro de 2006 a maio de 2008 atividade microbiana, são prováveis explicações para o melhor desempenho do sistema nos meses mais quentes. No caso do papel das macrófitas, cabe observar que os períodos mais quentes, em geral, coincidem com períodos mais longos de insolação e, portanto, isso pode também ter favorecido a atividade fotossintética.

As concentrações médias efluentes de NTK, separadas por fase operacional, estão resumidas na Figura 7, sendo possível perceber tendência de maior eficiência de remoção nas unidades com maior TDH (W1 e W2).

Os principais mecanismos responsáveis pela remoção de nitrogênio em WC são: nitrificação-desnitrificação, sedimentação de nitrogênio orgânico, assimilação por plantas (se mantida a frequência adequada de cortes), assimilação por micro-organismos e volatilização da amônia (em unidades de FS) (DUNNE; REDDY, 2005). Entretanto, permanecem incertezas sobre os mecanismos predominantes de remoção, cujas contribuições, muito provavelmente, variam segundo a configuração de cada sistema e as condições climáticas prevalentes. Koottatep e Polprasert (1997), na Tailândia, atribuíram à assimilação pelas plantas cerca de 50 a 70\% da remoção de nitrogênio total. Por outro lado, estudos realizados no Canadá demonstram que o corte regular das taboas foi responsável por apenas cerca de 10\% da remoção do nitrogênio total, sendo o processo de nitrificação-desnitrificação responsável por 25 a 85\% (REED et al., 1995).

Com relação ao fósforo, os principais mecanismos de remoção em WC são: armazenamento na biomassa vegetal e microbiológica, precipitação de compostos insolúveis e adsorção ao substrato. Brix et al. (1994) sugerem que a adsorção seja o mecanismo predominante, o qual é passível de saturação (TANNER; SUKIAS; UPSDELL, 1999), o que ajudaria explicar a queda de desempenho ao longo do período de operação.

A partir dos dados de produtividade e bromatológicos obtidos para as unidades plantadas com Brachiaria, foi possível estimar, para as Fases 2 e 3, a contribuição proporcional dessa macrófita na remoção total de nitrogênio e fósforo:

(i) nitrogênio: entre cerca de 3 a 13\% e excepcionalmente 44\% (W3, Fase 2);

(ii) fósforo: entre cerca de 7 a 30\% e excepcionalmente 69\% (novamente na unidade 3, Fase 2) (Tabela 4).

Tabela 4 - Contribuição da Brachiaria na remoção de nitrogênio e fósforo nas fases operacionais 2 e 3, Unidade Experimental de Tratamento de Esgotos e Utilização de Efluentes da Violeira, Viçosa (MG), agosto de 2007 a junho de 2008

\begin{tabular}{|c|c|c|c|c|c|c|c|c|}
\hline \multirow{3}{*}{ Parâmetro } & \multicolumn{4}{|c|}{ W2 } & \multicolumn{4}{|c|}{ W3 } \\
\hline & \multicolumn{2}{|c|}{ Fase 2} & \multicolumn{2}{|c|}{ Fase 3} & \multicolumn{2}{|c|}{ Fase 2} & \multicolumn{2}{|c|}{ Fase 3} \\
\hline & $\mathrm{N}$ & $P$ & $\mathrm{~N}$ & $\mathrm{P}$ & $\mathrm{N}$ & $\mathbf{P}$ & $\mathrm{N}$ & $\mathbf{P}$ \\
\hline Remoção total (kg) & 4,83 & 0,73 & 9,86 & 1,7 & 1,55 & 0,3 & 6,45 & 0,68 \\
\hline Remoção pelas plantas $(\mathrm{kg})$ & 0,63 & 0,22 & 0,47 & 0,14 & 0,69 & 0,21 & 0,17 & 0,05 \\
\hline \% de remoção pelas plantas em relação à remoção total & 13,04 & 30,09 & 4,76 & 8,94 & 44,14 & 69,14 & 2,65 & 6,7 \\
\hline
\end{tabular}




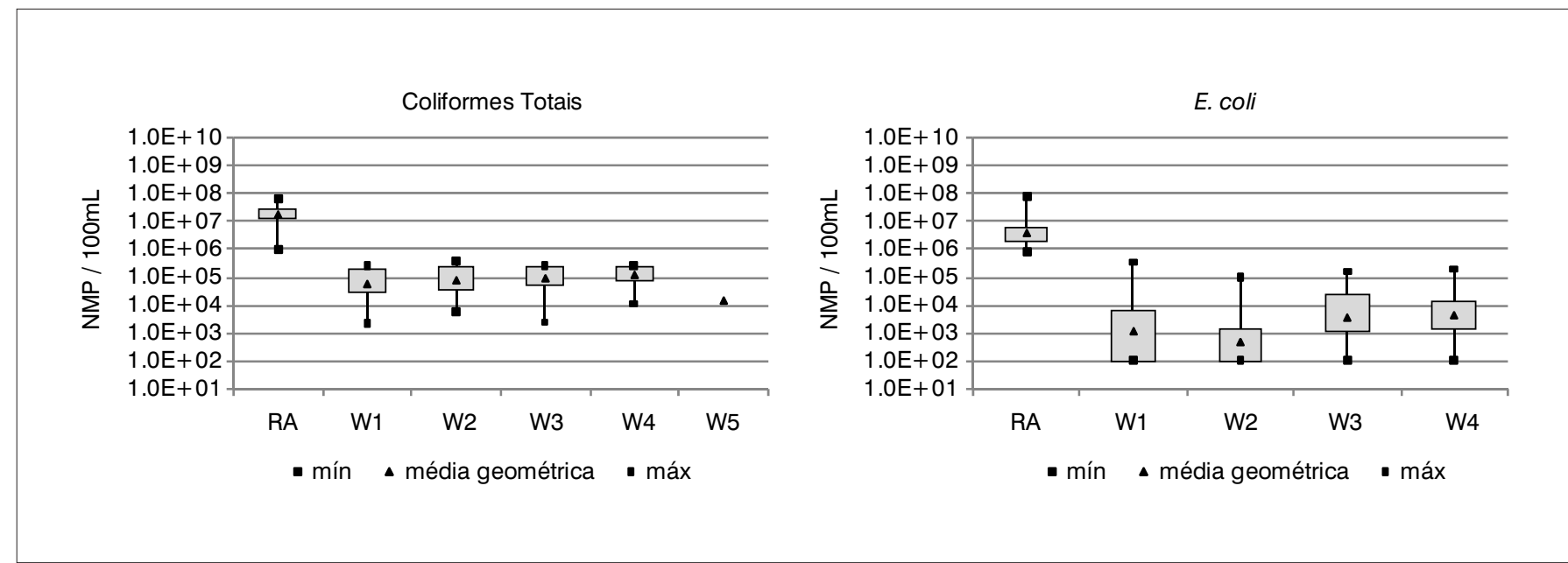

Figura 8 - Variação das concentrações de coliformes totais e $E$. coli nos efluentes do reator UASB e das wetlands, Unidade Experimental de Tratamento de Esgotos e Utilização de Efluentes da Violeira, Viçosa (MG), novembro de 2006 a maio de 2008

Os valores discrepantes na unidade 3, Fase 2 (mais elevados), poderiam ser creditados ao fato das remoções totais de nitrogênio e de fósforo terem sido, em si, relativamente mais baixas, pois a remoção por parte da braquiária em kg apresenta-se em valores mais consistentes em relação aos demais.

Brasil (2005), na mesma cidade do presente trabalho, em um sistema plantado com Typha sp., registraram que, 226 dias após o plantio, a remoção de nutrientes por meio da remoção da biomassa não foi muito expressiva (1,69 e 1,64\%, do aporte de N-total e P-total, respectivamente). Entretanto, outros trabalhos registram efetiva remoção de nutrientes pela biomassa de macrófitas, por exemplo, Koottatep e Polprasert (1997), em um sistema na Tailândia cultivado com Typha augustifoli.

\section{Remoção de coliformes totais e $E$. coli}

As concentrações de coliformes totais (CT) e E. coli nos efluentes das unidades de tratamento estão apresentados na forma de gráficos boxplot na Figura 8. O efluente do reator UASB apresentou média geométrica entre $10^{7}$ e $10^{8} \mathrm{CT}$ por $100 \mathrm{~mL}$; as WC alcançaram remoção de pouco mais de duas unidades logarítmicas (em termos percentuais, entre 99,20\% e 99,79\%), resultando em efluentes com médias geométricas próximas de $10^{5} \mathrm{CT}$ por $100 \mathrm{~mL}$. As diferentes unidades e fases operacionais apresentaram variações relativamente reduzidas, sugerindo pequena influência das diferentes taxas de aplicação hidráulica e do TDH.

A concentração média de E. coli no reator UASB esteve entre $10^{6}$ e $10^{7}$ organismos por $100 \mathrm{~mL}$; a remoção de E. coli nas WC foi mais acentuada (duas a quatro unidades logarítmicas) que a de CT, resultando em efluentes com médias geométricas de $10^{2}$ e $10^{4}$ E. coli por 100 mL (remoção percentual entre 99,72 a 99,99\%). No entanto, as variações de eficiência de remoção foram mais amplas que as de CT.
Os mecanismos ou fatores determinantes na remoção de coliformes em WC incluem temperatura, retenção nas raízes das plantas e no biofilme, adsorção à matéria orgânica, predação, competição e morte natural, efeito biocida resultante do material excretado por algumas macrófitas e radiação solar. Entretanto, ainda não há modelos consolidados de estimativa de decaimento bacteriano em WC (RIVERA et al., 1995; USEPA, 1988; KHATIWAD, POLPRASERT, 1999; KADLEC et al., 2000; KARIM et al., 2004).

Em linhas gerais, como critérios de projeto para WC, são utilizados TDH entre 5 e 14 dias (FS) e 2 e 7 dias (FSS) e taxas de aplicação hidráulica de 7 a $60 \mathrm{~mm} \cdot \mathrm{d}^{-1}$ (FS) e 2 a $30 \mathrm{~mm} \cdot \mathrm{d}^{-1}$ (FSS). Vários trabalhos indicam remoção de coliformes termotolerantes de 1 a $2 \log _{10}$ em sitemas de FSS com TDH entre três e seis dias (USEPA, 1988; GERSBERG; GEARHEART; IVES, 1989; THURSTON et al., 2001; VALENTIM, 2003). Para sistemas de FS, há sugestões de que, para remoção de 1 a $2 \log _{10}$, são necessários TDH de 6 a 10 dias (USEPA, 1988; MERZ, 2000). Gersberg et al. (1989), na Califórnia (EUA), indicam que WC com TDH de 3 a 6 dias podem alcançar 90 a 99\% de remoção de coliformes termotolerantes (CTer). Molleda et al. (2008), na Espanha, registraram 97 a 99,9\% de remoção de E. coli. Thurston et al. (2001), no Estado do Arizona (EUA), pesquisaram WC de FSS com TDH de 4 dias e obtiveram remoção de CTer de 98,8\%. No Brasil, Sousa et al. (2004) encontraram remoção de CTer de cerca de $4 \log _{10}$, com TAS = 23 mm.d d $^{-1}$ e TDH = 10 dias. Brasil (2005), em Viçosa, reporta remoção de CTer de 95\% (TDH = 1,9 dias e TAS $=70$ - $\left.120 \mathrm{~mm} \cdot \mathrm{d}^{-1}\right)$ e 99,9\% (TDH = 3,6 dias e TAS $\left.\approx 45 \mathrm{~mm} \cdot \mathrm{d}^{-1}\right)$. No presente trabalho, em resumo, tanto as WC de FS ( $\mathrm{TDH}=4,5$ dias e TAS $\approx 63 \mathrm{~mm} \cdot \mathrm{d}^{-1}$ ) quanto as de FSS (TDH $=1,3-5,4$ dias e TAS $\approx 42$ - $170 \mathrm{~mm} \cdot \mathrm{d}^{-1}$ ) alcançaram cerca de 2,5 a $4 \log _{10}$ de remoção de E. coli. Os resultados indicam ainda que as unidades com maior TDH (W1 e W2) apresentaram, em geral, maior eficiência, principalmente nas Fases 1 e 2, quando os TDH foram superiores a três dias. 

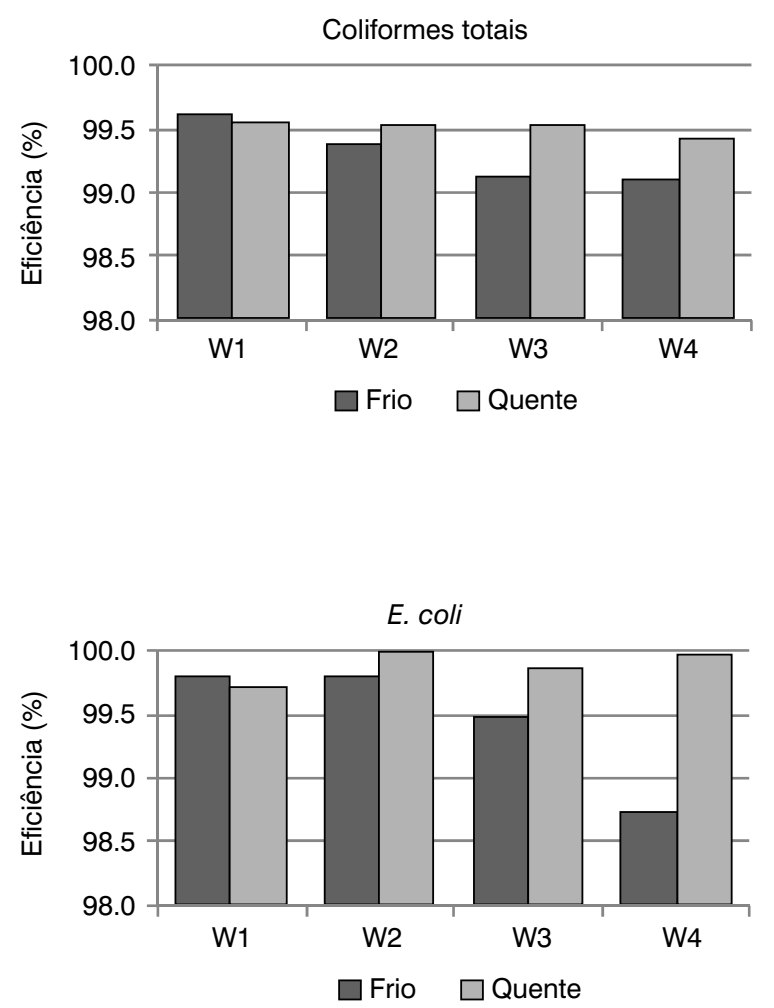

Figura 9 - Média das eficiências de remoção de coliformes totais e de $E$. coli nas wetlands nos meses mais frios e mais quentes, Unidade Experimental de Tratamento de Esgotos e Utilização de Efluentes da Violeira, Viçosa (MG), novembro de 2006 a maio de 2008

Sobre as variações sazonais, alguns autores observam maiores eficiências durante o verão (EL HAMOURI et al., 1994; KARATHANASIS et al., 2003), outros não (GARCÍA et al., 2006). Os resultados do presente estudo mostraram alguma tendência à melhor eficiência no período mais quente, principalmente nas W3 e W4 (Figura 9), embora as diferenças não tenham chegado a uma unidade logarítmica, tanto para coliformes totais quanto para E. coli.

A eficiência alcançada nas unidades W1 e W2 na remoção de coliformes totais e E. coli na Fase 2 (FSS) foi similar à observada na Fase 1 (FS), sugerindo que sistemas de FSS podem ser tão eficientes quanto os de FS, descartando-se, assim, eventuais vantagem associadas às unidades de FS, por incluírem efeitos da radiação UV dentre os mecanismos de remoção. Assim, excluídos os fatores para os quais não há indícios de forte influência da remoção de coliformes (temperatura, radiação solar), resta especular que esta tenha se dado como efeito conjugado das demais variáveis usualmente consideradas: retenção nas raízes das plantas e no biofilme, adsorção à matéria orgânica, predação, competição e morte natural, efeito biocida resultante do material excretado pelas macrófitas.

\section{Conclusões}

Sob as condições operacionais testadas neste trabalho, wetlands construídas de fluxo horizontal (WCFH) revelaram elevada capacidade e estabilidade de remoção de DBO e SST, confirmando entendimentos consolidados na literatura especializada. Os resultados obtidos confirmam também que WCFH dimensionadas para a remoção de nitrogênio produzem efluentes de excelente qualidade em termos de DBO e SST.

Entretanto, a remoção de nutrientes ( $\mathrm{N}$ e P) mostrou-se limitada, com amplas variações nas concentrações efluentes de nitrogênio em torno do padrão assumido como critério de projeto (20 $\mathrm{mg} \mathrm{NH}_{3} \cdot \mathrm{L}^{-1}$ ), além de sinais de queda de desempenho em períodos mais longos de operação e variações sazonais aparentemente influenciadas pela temperatura.

Em relação à remoção de E. coli, as WCFH apresentaram desempenho superior ao usualmente reportado na literatura para países de clima temperado e consistente com resultados de outros trabalhos conduzidos no Brasil, entretanto, com variações relativamente amplas.

Os resultados obtidos indicam a necessidade de estudos complementares, no sentido de melhor compreensão dos mecanismos determinantes na remoção de nutrientes e bactérias do grupo coliforme em WC, de forma a subsidiar a formulação/consolidação de critérios de dimensionamento.

\section{Agradecimentos}

Os autores agradecem à Fundação de Amparo à Pesquisa do Estado de Minas Gerais (Fapemig) e ao Conselho Nacional de Desenvolvimento Científico e Tecnológico (CNPq) pela concessão de recursos financeiros e/ou bolsas de Iniciação Científica; e ao Serviço Autônomo de Água e Esgotos (SAAE) de Viçosa, pelo apoio e parceria. 


\section{Referências}

APHA; AWWA; WEF. Standard methods for the examination of water and wastewater. 20 ed. Washington, D.C: APHA, AWWA, WEF, 1998.

BRASIL, M.S. Desempenho de sistema alagado construído para tratamento de esgoto doméstico. 2005. 160 f. Tese (Doutorado em Engenharia Agrícola) - Departamento de Engenharia Agrícola da UFV, Viçosa, 2005.

BRIX, H. Functions of macrophytes in constructed wetlands. Water Science and Technology. v. 29, n. 4, p. 71-78, 1994

CHERNICHARO, C.A.L. (Coord.) Pós-tratamento de reatores anaeróbios. Belo Horizonte: ABES, 2001. Projeto Prosab.

DUNNE, E.J.; REDDY, K.R. Phosphorus biogeochemistry of wetlands in agricultural watersheds. In: DUNNE, E.J.; REDDY, R.; CARTON, O.T. (Eds). Nutrient management in agricultural watersheds: a wetland solution. Wageningen, The Netherlands: Wageningen Academic Publishers, 2005. p. 105-119.

EL HAMOURI, B. et al. High-rate algal pond performances in faecal coliforms and helminth egg removals. Water Research, v. 26, n. 1, p. 171-174, 1994

GARCÍA, M. et al. A comparison of bacterial removal efficiencies in constructed wetlands and algae-based systems. In: INTERNATIONAL CONFERENCE ON WETLAND SYSTEMS FOR WATER POLLUTION CONTROL, Lisbon, Portugal: International Water Association - IWA, 2006. p. 355-365.

GERSBERG, R.M; GEARHEART, R.A.; IVES, M. Pathogen removal in constructed wetlands. In: HAMMER, D.A. (Ed). Constructed wetlands for wastewater treatment: municipal, industrial and agricultural. Chelsea, Michigan: Lewis Publishers, 1989. p. 431-445.

KADLEC, R. et al. Constructed wetlands for pollution control. Processes, performance, design and operation. London: IWA Publishing, 2000. Scientific and Technical Report Series, 8.

KARATHANASIS, A.D.; POTTER, C.L; COYNE, M.S. Vegetation effects on faecal bacteria, BOD and suspended solid removal in constructed wetlands treating domestic wastewater. Ecological Engineering, v. 20, p. 157-169, 2003.

KARIM, M.R. et al. The persistence and removal of enteric pathogens in constructed wetlands. Water Research, v. 38, n. 7, p. 1831-1837, 2004.

KHATIWAD, N.R.; POLPRASERT, C. Kinetics of fecal coliform removal in constructed wetlands. Water Science and Technology, v. 40, n. 3, p. 109-115, 1999.

KOOTTATEP, T.; POLPRASERT, C. Role of plant uptake on nitrogen removal in constructed wetlands located in the tropics. Water Science and Technology, v. 36, n. 12, p. 1-8, 1997.

MBWETTE, T.S.A; KATIMA, J.H.Y.; JØRGENSEN, S.E. (Eds.). Application of wetland systems and waste stabilization ponds in water pollution control. Dar es Salaam: Institute of Kiswahili Research, 2001.
MERZ, S.K. Guidelines for using free water surface constructed wetlands to treat municipal sewage. Brisbane: Department of Natural Resources, Government of Queensland, 2000. Disponível em: <http://www.epa qld.gov.au/publications/p00424aa.pdf/Guidelines_for_using_free water_surface_constructed_wetlands_to_treat_municipal_sewage.pdf $>$ Acesso em 24 set. 2008

MOLLEDA, P. et al. Removal of wastewater pathogen indicators in a constructed wetland in Leon, Spain. Ecological Engineering, v. 33, n. 3-4, p. 252-257, 2008.

NOGUEIRA, S.F. Balanço de nutrientes e avaliação de parâmetros biogeoquímicos em áreas alagadas construídas para o tratamento de esgoto. 2003. 139 f. Dissertação (Mestrado em Energia na Agricultura) Centro de Energia Nuclear na Agricultura da USP, Piracicaba, 2003.

NYAKANG'O, J.B.; van BRUGGEN, J.J.A. Combination of a well functioning constructed wetland with a pleasing landscape design in Nairobi, Kenya. Water Science and Technology, v. 40, n. 3, p. 249-247, 1999

REED, S.C.; CRITES, R.W.; MIDDLEBROOKS, E.J. Natural systems for waste management and treatment. 2 ed. New York: McGraw-Hill, 1995

RIVERA, F. et al. Removal of pathogens from wastewaters by the root zone method (RZM). Water Science and Technology, v. 32, n. 3, p. 211 218, 1995

SOUSA, J.T.; VAN HAANDEL, A.; LIMA, E.P.C. Use of constructed wetland for the post-treatment of domestic sewage anaerobic effluent from UASB reactor. Engenharia Sanitária e Ambiental, v. 9, n. 4, p. 285290,2004

STOTT, R.; MAY, E.; MARA, D.D. Parasite removal by natural wastewater treatment. Water Science and Technology, v. 48, n. 2, p. 97-104, 2003.

TANNER, C.C.; SUKIAS, J.P.S; UPSDELL, M.P. Substratum phosphorus accumulation during maturation of gravel-bed constructed. Water Science and Technology, v. 40, n. 3, p. 147-154, 1999

THURSTON, J.A. et al. Fate of indicator microorganisms, Giardia and Cryptosporidium in subsurface flow constructed wetlands. Water Research, v. 35, n. 6, p. 1547-1551, 2001.

UNITED STATES ENVIRONMENTAL PROTECTION AGENCY, USEPA Manual: Constructed wetlands treatment of municipal wastewater Cincinnati, Ohio: Usepa, Office of Research and Development, 2000. (EPA/625/R-99/010). Disponível em: http://www.epa.gov/owow/wetlands/ pdf/Design Manual2000.pdf. Acesso em: 15 set. 2008.

Design manual: constructed wetlands and aquatic plant systems for municipal wastewater treatment. Cincinnati, Ohio: Usepa, Office of Research and Development, 1988 (EPA/625/1-88/022). Disponível em: <http://www.epa.gov/owow/wetlands/pdf/design.pdf> Acesso em: 15 set. 2008

VALENTIM, M.A.A. Desempenho de leitos cultivados ("constructed wetland") para tratamento de esgoto: contribuições para concepção 
e operação. 2003. 210 f. Tese (Doutorado em Engenharia Agrícola) Faculdade de Engenharia Agrícola da Unicamp, Campinas, 2003

Uso de leitos cultivados no tratamento de efluente de tanque séptico modificado. 1999. 120 f. Dissertação (Mestrado em Engenharia Agrícola) - Faculdade de Engenharia Agrícola da Unicamp, 1999.
VYMAZAL, J. Constructed wetlands for wastewater treatment in the Czech Republic the first 5 years experience. Water Science and Technology, $v$. 34, n. 11, p. 159-164, 1996.

VYMAZAL, J. Removal of phosphorus in constructed wetlands with horizontal sub-surface flow in the Czech Republic. Water, Air, \& Soil Pollution: Focus, v. 4, n. 2-3, p. 657-670, 2004. 